\title{
Alfabetización mediática y aprendizaje. Aporte conceptual en el campo de la comunicación-educación ${ }^{1}$
}

\author{
Media Literacy and Learning. Conceptual Contribution in the Field of Media Education ${ }^{2}$ \\ Alfabetização midiática e aprendizagem. Contribuição conceitual no campo da \\ comunicação-educação ${ }^{3}$
}

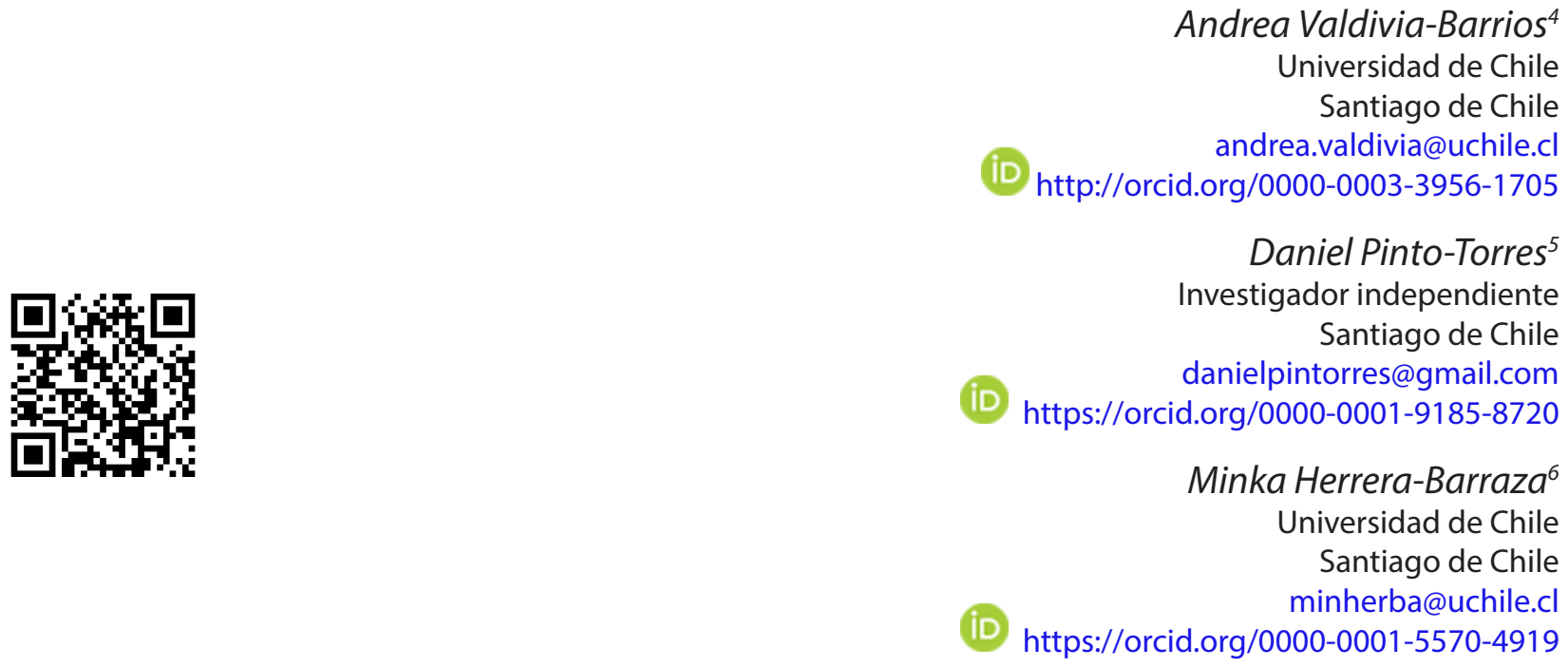

Recibido • Received • Recebido: 31 / 10 / 2016

Corregido • Revised • Revisado: 04 / 02 / 2018

Aceptado • Accepted • Aprovado: 19/02 / 2018

\footnotetext{
${ }^{1}$ Artículo realizado en el marco del Proyecto FONDECYT N. ${ }^{\circ} 11130640$, Universidad de Chile, y financiado por CONICYT Chile.

${ }^{2}$ This work was made in the framework of FONDECYT Initiation Project n. 11130640 Universidad de Chile, with support by CONICYT Chile.

${ }^{3}$ Artigo elaborado no âmbito do Projeto FONDECYT No. 11130640, Universidade do Chile, e financiado pela CONICYT Chile.

${ }^{4}$ Antropóloga social y doctora en educación. Académica del Instituto de la Comunicación en Imagen de la Universidad de Chile. Su trabajo de investigación se inscribe en el campo de la comunicación - educación, centrado en el aprendizaje, las identidades y las prácticas mediáticas de jóvenes. Sus publicaciones abordan la alfabetización, las prácticas pedagógicas, la producción mediática, la etnografía y la interculturalidad.

${ }^{5}$ Licenciado en Sociología de la Universidad de Chile. Investigador con 5 años de experiencia en temáticas relativas a nuevas tecnologías de información y comunicación, competencias digitales y mediales, análisis de audiencias, políticas en comunicación y participación ciudadana digital. También se ha desempeñado como tallerista en instancias de educación en medios y participación ciudadana para jóvenes.

${ }^{6}$ Educadora de Párvulos y Escolares Iniciales y Magister en Psicología Educacional de la Universidad de Chile. Actualmente es asistente de la Dirección de Investigación del Instituto de la Comunicación e Imagen. Ha sido ayudante de investigación y de cátedras de pre y postgrado. Investiga etnográficamente el aprendizaje en los procesos de creación en jóvenes, con publicación sobre el mismo tema.
} 
doi: http://dx.doi.org/10.15359/ree.22-2.8

URL: http://www.una.ac.cr/educare

CORREO: educare@una.cr

Resumen: Las transformaciones sociales relacionadas con las tecnologías digitales y los nuevos medios ofrecen importantes desafíos a la educación. La escuela deja de ser el espacio protagónico, las formas de conocer y producir conocimiento se amplían y diversifican, y las prácticas comunicativas se complejizan. Esto hace necesario examinar las habilidades y aprendizajes que se deben promover para actuar y participar en los escenarios mediáticos y digitales. El artículo presenta una revisión conceptual crítica sobre alfabetización mediática y aprendizaje desde tradiciones latinoamericanas, estadounidenses y europeas, a partir de la recopilación y análisis de publicaciones que tratan las dos últimas décadas. Se propone una lectura que integra aportes teóricos tanto de la comunicación como de la educación. La alfabetización se entiende como una práctica social que implica construcción y consenso social para la generación y negociación de significados, gracias a la mediación del lenguaje; procesos que se logran a partir del aprendizaje.

Palabras claves: Alfabetización mediática; aprendizaje; competencias; lenguaje; prácticas mediáticas; tecnologías digitales.

Abstract: The social transformations related to digital technologies and new media offer important challenges to education. The school ceases to be the main space; ways of knowing and producing knowledge expand and diversify; and communicative practices become more complex. This makes it necessary to examine skills and learnings that should be promoted to act and participate in digital and media settings. This article presents a critical conceptual review on media literacy and learning from Latin American, American and European traditions. A reading integrating theoretical contribution from communication and education is proposed. Literacy is understood as a social practice that implies construction and social consensus for the generation and negotiation of meanings through language and learning. It offers pertinent guidelines for an educational curriculum in tune with the challenges of digitization and mediatization of society.

Keywords: Media literacy; learning; competences; language; media practices; digital technologies.

Resumo: As transformações sociais relacionadas com as tecnologias digitais e novos meios oferecem desafios significativos para a educação. $O$ espaço da escola deixa de ser protagonista, as formas de conhecer e produzir conhecimento se ampliam e se diversificam, as práticas de comunicação ficam más complexas. Isso torna necessário examinar as habilidades e aprendizagens que devem ser promovidas para atuar e participar nos espaços midiáticos e digitais. $\mathrm{O}$ artigo apresenta uma revisão crítica conceitual sobre a alfabetização midiática e aprendizagem, a partir das tradições Latinoamericanas, estadunidenses e europeias, a partir da coleta e análise de publicações realizadas nas últimas duas décadas. A proposta que se faz é de uma leitura que integra contribuições teóricas, tanto no campo da comunicação como da educação. A alfabetização é entendida como uma prática social que envolve a construção e o consenso social para a geração e negociação de significados, graças à mediação da linguagem; processos que são alcançados através da aprendizagem.

Palavras-chave: Alfabetização midiática; aprendizagem; competências; linguagem; práticas midiáticas; tecnologias digitais. 


\section{Introducción}

El desarrollo de las tecnologías digitales y la relevancia que adoptan los nuevos medios de comunicación en la vida cotidiana de gran parte de la población han implicado transformaciones sociales y culturales con importantes desafíos para la educación. La mayoría de niños, niñas y adolescentes de hoy nacieron en un mundo altamente mediatizado, donde las pantallas están presentes en sus diversos espacios y rutinas. Todas estas transformaciones que se manifiestan con claridad en las prácticas mediáticas están implicando nuevos aprendizajes que involucran aspectos técnicos, sociales, semióticos, estéticos, y éticos (Buckingham, 2007; Gee y Hayes, 2011).

Uno de los principales cambios relaciona los procesos comunicativos y la mediación de tecnologías, hoy, gracias a la expansión de la internet y la generación de tecnologías audiovisuales digitales, existe la posibilidad de producir y crear contenidos "caseros", y de ponerlos en circulación en diversas plataformas mediáticas. De tal forma, los llamados social media ${ }^{7}$ o los medios asociados a la web 2.0 favorecen el cuestionamiento de la clásica relación lineal y rígida (Ardévol, Gómez-Cruz, Roig y San Cornelio, 2010), propia de los medios de comunicación de masas, donde la acción de los sujetos estaba centrada en la recepción de contenidos creados por un grupo reducido de personal productor experto. Este nuevo escenario favorece no solo la participación y el desarrollo pleno en los mensajes emitidos y transmitidos, sino también, las posibilidades de producir dichos mensajes, dominar las herramientas y patrones técnicos, semióticos y estéticos que permiten producir contenidos mediáticos digitales.

Para la comprensión de las transformaciones se requiere de la revisión y discusión de los constructos teóricos y conceptuales con que se han abordado tradicionalmente los fenómenos educativos, sociales y comunicativos implicados. Este artículo tiene como propósito revisar el recorrido hecho en este ámbito situado en la intersección entre dos campos que comparten una configuración interdisciplinaria: comunicación y educación. Se presta especial atención a uno de los fenómenos que cobra relevancia en el actual escenario mediático, la alfabetización.

Las prácticas mediáticas suponen el dominio de un conjunto de habilidades y conocimientos; disposiciones y actitudes, que permiten la acción cotidiana orientada hacia los medios o en relación con ellos (Couldry, 2004). En ese sentido, las transformaciones tecnológicas y culturales tensionan las formas en que se ha concebido el proceso de adquisición y desarrollo de los lenguajes implicados. ¿Qué implica ser una persona alfabetizada en el actual contexto histórico?, ¿cuál es el objeto de la alfabetización?, o en otras palabras, ¿qué sistemas semióticos están implicados en los lenguajes a alfabetizar y movilizar en las prácticas mediáticas? Todas

\footnotetext{
${ }^{7}$ Se opta por el término original en inglés, al igual que las personas autoras referenciadas (Ardévol, et al, 2010) para evitar la pérdida de sentidos que muchas veces provoca la traducción. De hecho, el mismo término media hace referencia a todo el proceso comunicativo mediado y no solo a los medios de comunicación implicados, acepción que se encuentra en alguna literatura en español.
} 
doi: http://dx.doi.org/10.15359/ree.22-2.8

URL: http://www.una.ac.cr/educare

CORREO: educare@una.cr

estas interrogantes traen la pregunta más general sobre el aprendizaje, en términos del proceso que permite la adquisición y desarrollo de conocimientos, valores, habilidades y disposiciones, en este caso mediáticas, que ocurren en contextos formales e informales. Con ello, se apunta, además, al descentramiento de lo educativo en lo propiamente escolar.

Introducir el aprendizaje en la discusión sobre las alfabetizaciones mediáticas pretende hacer confluir los aportes teóricos de ambos campos, comunicación y educación, y comprender que los objetos centrales de cada uno, construcción de sentido en comunicación y aprendizaje en educación, están mutuamente implicados. Tal como señala De Fontcuberta (2001), todo proceso educativo tiene en la base una acción comunicativa. En la línea sociohistórica que se sigue acá, el aprendizaje y el desarrollo humano se inician y potencian a partir de la adquisición del lenguaje y la construcción de sentido del sí y del mundo.

El artículo primero revisa los recorridos teóricos y conceptuales que han dado vida al campo o espacio de intersección comunicación-educación, y las tensiones que hoy vivencia. Luego, se desarrolla la discusión conceptual sobre alfabetización mediática, evidenciando la polifonía existente; se presenta el concepto de competencia mediática, el que adquiere cierta relevancia y ha sido asociado a la alfabetización. Finalmente, se aborda el aprendizaje en las prácticas mediáticas como fenómeno situado en contextos históricos determinados, y donde el lenguaje es aquella herramienta que favorece la alfabetización, y se desarrolla a partir de ella.

\section{Las trayectorias teórico-conceptuales en comunicación-educación}

Los estudios de la comunicación en las últimas décadas generaron un cuerpo de conocimiento teórico y práctico en torno a la relación entre educación y comunicación, problematizando en especial el papel de los medios de comunicación de masas en el desarrollo de la niñez y la juventud, y en las formas de su inclusión en las prácticas educativas. Ahora, para algunos estudios, como el de Leaning (2009), esto aún no logra solidez ni consenso transversal en la comunidad de investigadores e investigadoras.

Desde América Latina, se desarrolla una corriente que recoge influyentes trabajos como los de Martín-Barbero $(2002,2003)$ en el estudio de la diada comunicación-cultura desde una perspectiva crítica. Un aporte fundamental fue dar profundidad y complejidad a la comunicación donde el foco se aleja de los medios de comunicación de masas y se amplía a los procesos de mediación y significación de los sujetos en relación con los medios. Un propósito clave era cuestionar lo instituido en las lógicas hegemónicas de la cultura y de los marcos de investigación en comunicación. Se acuña el término edu-comunicación desde donde se construye no solo un marco de conocimientos teóricos, sino también un acumulado de experiencias educativas, tanto en el espacio formal como no formal. 
A partir de ese trabajo se plantea la intersección entre comunicación-educación como un campo nuevo, donde confluyen diversas perspectivas teóricas y prácticas sociales y profesionales con intereses distintos (Huergo, 2000; Valderrama, 2000). Siendo tanto la comunicación y la educación campos ya definidos por su interdisciplinariedad, cabe preguntarse cómo el espacio de encuentro e intersección entre ellos se transforma en un nuevo campo, que por cierto comparte este carácter interdisciplinario. Una respuesta puede estar en la concepción que detentan estudios convencidos de su existencia, donde la confluencia de diversas perspectivas implica la disputa entre discursos y prácticas hegemónicas y contra-hegemónicas sobre los objetos propios de este naciente campo (Espitia y Valderrama, 2009). Esta caracterización de un espacio en disputa se acerca al concepto de campo de Bourdieu, por lo que tendría sentido desde esa perspectiva. Sin embargo, puede ser insuficiente para delimitar con claridad qué es aquello que lo particulariza respecto a cada uno de los campos del que es tributario. Esto, a pesar de lo que plantean otras investigaciones más recientes: Morabes (2014) concibe el vínculo entre comunicación y educación de un modo articulatorio, lo que implica que las identidades de cada uno se modifiquen a causa de la relación.

Según Huergo (2000) y Valderrama (2000), es posible organizar las trayectorias teóricas y prácticas en las siguientes líneas: educación para la recepción, comunicación en la educación y educación y nuevas tecnologías.

La educación para la recepción desde los años 60 tiene una influencia significativa hasta incluso entrado el presente siglo. Las propuestas iniciales se sustentaron en el modelo clásico de la comunicación, con lógica lineal de emisor-mensaje-receptor. A fines de los setenta se da paso a visiones críticas tanto de los medios como de las posibilidades de la audiencia. En esta línea se encuentran los aportes de la lectura crítica de medios, los estudios de recepción activa (CENECA, 1992), y los de educación de audiencias (Valderrama, 2000).

Como se verá más adelante, es posible identificar algunas convergencias entre los últimos aportes y la Media literacy, propuesta anglosajona en donde los medios de comunicación son importantes creadores y mediadores del conocimiento que circula en las sociedades y las representaciones de la realidad. El foco está en el análisis crítico de los productos mediáticos.

Como se aprecia, la relación comunicativa que supone esta línea sostiene una dicotomía entre ente productor y público receptor, por muy activo que este sea. La educación es vista, entonces, como el medio que permite lograr la recepción activa o crítica, y la formación de las audiencias, esto es, dar racionalidad y reflexividad a la experiencia mediática.

Los medios que acá se perfilan son los masivos. Y, si bien es cierto, la influencia y presencia en las prácticas mediáticas cotidianas aún es significativa, los aportes teóricos y conceptuales que están en esta línea no logran dar cobertura ni comprensión total a los fenómenos actuales, donde los social media han resituado la relación con los medios y la posición de la audiencia. De hecho, en estos casos, se cuestiona el uso del concepto de audiencia. 
doi: http://dx.doi.org/10.15359/ree.22-2.8

URL: http://www.una.ac.cr/educare

CORREO: educare@una.cr

Por su parte, la comunicación en la educación, segundo ámbito identificado por Valderrama (2000), se centra en las dinámicas comunicativas que subyacen en la relación pedagógica y en la interacción de los actores del proceso enseñanza-aprendizaje, tanto dentro como fuera de la institución escolar. De manera contemporánea al desarrollo del anterior ámbito, los trabajos de Freire (1999) y Kaplún (1987) plantean propuestas de trabajo con comunidades que apuntan a la transformación de la relación binaria, transmisiva y de opresión. La comunicación y educación popular fueron desarrolladas en sus orígenes para contextos extraescolares, pero rápidamente se intentó introducir en la escuela.

Aunque Valderrama (2000) no las considera, se pueden vincular, a este ámbito, las líneas de investigación que, desde la pedagogía, la psicología del desarrollo y la investigación en educación, tienen sus objetos en la comunicación dentro de los procesos educativos. En este plano se encuentran los aportes de Vygotski (1978) y la psicología sociocultural (Wertsch, 1999), la investigación del discurso en el aula (Cazden, 1991) y los estudios que abordan las interacciones educativas (Mercer, 1997). Se incluyen estos aportes, pues permiten visualizar la conexión entre los campos, valorando los aportes que desde educación se pueden hacer a este ámbito.

El ámbito de la educación y nuevas tecnologías surge, siguiendo a Valderrama (2000), desde la reflexión acerca del lugar de las nuevas tecnologías en la cultura; el devenir de las sociedades y el impacto en la educación, y los procesos cognitivos. Es probable que este sea uno de los ámbitos que ha tenido, en los últimos años, mayor desarrollo, tanto al interior del campo de la comunicación-educación, como en cada uno de ellos. Si bien Valderrama (2000) señala que los estudios en este ámbito están enfocados principalmente en el desarrollo tecnológico y las habilidades y menos en la incorporación de la dimensión de la comunicación y de los contextos culturales, en la actualidad es posible encontrar algunas experiencias y programas de investigación que sí avanzan en la configuración del problema comunicativo - educativo del uso de las TIC.

Por último, Huergo (2000) propone un cuarto ámbito, lo que él denomina instituciones educativas y horizontes culturales. Aquí lo que se pretende es descentrar la discusión de los medios de comunicación, para ponerla en el espacio de la cultura y la comunicación, como construcción de sentido. El autor aborda las tensiones entre la cultura escolar y la cultura mediática (Huergo y Fernández, 1999).

Como se aprecia, si bien el cuerpo teórico desarrollado desde América Latina logra cierta estabilidad y coherencia en la comprensión de los fenómenos edu-comunicativos, su pertinencia está más relacionada con las prácticas mediáticas que devienen previo a las transformaciones actuales. Un segundo aspecto que merece revisión es el menor diálogo que se hace con los aportes de la investigación en educación, y con las discusiones teórico-conceptuales generadas en países anglosajones. 
A continuación, se hará una revisión del término alfabetización mediática que pretende ser más abarcadora en perspectivas, mostrando a su vez, la complejidad presente en el campo, para articular aproximaciones consistentes.

\section{Alfabetización y competencia mediática. Precisiones conceptuales}

La relevancia que adopta el concepto de alfabetización en el campo de la comunicacióneducación surge por la posición, desde diversos sectores de la sociedad, de avanzar en la educación en medios para promover un uso más provechoso de estas herramientas (AguadedGómez, 2012). Esta tarea de formar a la ciudadanía para un consumo y unas prácticas mediáticas más diversas y conscientes tuvo un punto de partida con la Declaración de Grünwald, realizada por UNESCO en 1982 (Pérez, 2007), la cual exhorta a los gobiernos a desarrollar la educación en medios, con el fin de que los sujetos sean más críticos de aquellos contenidos que consumen y, a la vez, tengan la capacidad de ser productores y participar en el espacio público constituido por los mensajes mediáticos que circulan.

De este inicio surge el concepto que condensa el propósito de la educación en medios, alfabetización mediática, o media literacy, definida como habilidad de acceder, analizar, evaluar y comunicar mensajes en una variedad de formas (Aufderheide, en Potter, 2010). A esta breve definición se acogen, con matices, la mayoría de los trabajos que abordan el tema. A pesar de esa alta aceptación vale la pena revisar algunos aspectos que pueden parecer ambiguos, pues tal como plantean Buitrago, García y Gutiérrez (2017), la diversidad terminológica dentro del campo de la edu-comunicación hace necesaria la revisión conceptual para aclarar el panorama. Recogiendo ese llamado, a continuación, se delimitarán algunos conceptos involucrados, partiendo por el de alfabetización.

\section{Alfabetización o alfabetizaciones}

En el idioma inglés, la palabra literacy, de acuerdo con el English Oxford Living Dictionaries (s.f.) corresponde tanto a la "habilidad para leery escribir", como a"la competencia o conocimiento en un área específica" y se traduce al español con el término alfabetización.

Esta traducción ha presentado algunos inconvenientes, pues tal como plantean Buitrago et al. (2017), es inadecuada pues ambos términos parecieran apuntar a fenómenos distintos aunque estrechamente relacionados: alfabetización como un producto del proceso educativo, o alfabetización como el proceso en sí mismo. Otro aspecto que resulta complejo de esta traducción tiene que ver con la carga que porta el término en castellano y que tiende a ser circunscrito de manera rápida a la lecto-escritura, mientras que literacyal desarrollo y adquisición de diversos lenguajes. 
doi: http://dx.doi.org/10.15359/ree.22-2.8

URL: http://www.una.ac.cr/educare

CORREO: educare@una.cr

Teniendo lo anterior presente, se debe señalar que el uso en castellano del vocablo alfabetización asociado a lo mediático tiene un sentido eminentemente político. Hug (2013) plantea que la utilización del término tiene la intención metafórica de indicar la similitud del proceso de dominio del código de la lecto-escritura con el de otros lenguajes (visual, audiovisual, etc.); pero, además, supondría una intención de asignar estratégicamente la importancia o la urgencia al dominio de determinadas habilidades en un mundo que impone determinados lenguajes. En la misma línea, Wilson (2012) puntualiza que los desafíos del siglo XXI hacen insuficiente la alfabetización lecto-escritora, y resulta imperativa una alfabetización más amplia como una cuestión de justicia, y Livingstone (2004) agrega que la alfabetización mediática es parte de un paquete de medidas para iluminar 'desde arriba' la regulación de los medios, devolviendo la responsabilidad por el uso mediático desde el Estado a los individuos.

Ya sea por razones conceptuales o políticas, la apertura del concepto ha allanado el camino para la postulación de diversos tipos de alfabetización. Aparecen líneas de investigación en torno a "alfabetizaciones múltiples", que se enlazan en mayor o en menor medida con lo mediático (Buitrago et al., 2017). La idea de que el dominio de los códigos de lecto-escritura sea un proceso que se asemeja a otros que ocurren en otros ámbitos explica, en parte, que, además de la alfabetización mediática, surjan conceptos tales como new media literacy, digital literacy, information literacy (Catts y Lau, 2008; Koltay, 2011; Literat, 2014).

Ante esta explosión de propuestas de nuevas alfabetizaciones, aparecen respuestas que plantean que, en realidad, se trata de "multi-alfabetizaciones"; es decir, saberes unificados, que se condensan en ciertos conceptos aglutinantes. Gutiérrez y Tyner (2012) sostienen que es riesgosa la proliferación de términos, no solo por la confusión que causa, sino que también porque se corre el riesgo de privilegiar algunas dimensiones -específicamente las más "técnicas"- por sobre otras. En ese sentido, llaman a la convergencia terminológica, adhiriendo a las posturas que promueven la inclusión de todas esas dimensiones en el término alfabetización mediática.

En el esfuerzo por generar consenso y lenguaje común, dos propuestas resultan particularmente relevantes por el impacto que han causado a nivel de discusión académica dentro del campo de la comunicación-educación.

Por una parte, se encuentra la propuesta de UNESCO de la alfabetización mediática e informacional (AMI o MIL, en inglés), que integra las corrientes de la alfabetización mediática con la de la información, buscando un abordaje holístico que remita no solo a los medios de comunicación (y sus contenidos mediatizados o publicados), sino que también otros entes proveedores de información (Buitrago et al., 2017; Wilson, 2012). Aquella integración se considera un "salto adelante cualitativo" (Pérez-Tornero y Tayie, 2012, p. 12) dentro de la educomunicación. Sin perjuicio de lo anterior, la amplitud de sus propósitos, reflejados en el currículo MIL (Wilson et al., 2011) y las habilidades -competencias- que promueve deben traducirse a la 
hora de implementarse en prácticas educativas específicas (Wilson, 2012) y particularizadas (a modo de desarrollo de la literacidad, como se verá más abajo), por lo que pareciera ser más útil como marco de referencia general para políticas nacionales, especialmente en realidades donde el desarrollo tecnológico y social es precario (Saleh, 2012).

Por otra parte, se encuentra la propuesta formulada por Ferrés (2007) en España, quien habla de competencia en comunicación audiovisual, retomada por Pérez y Delgado (2012) quienes, en el afán de no fraccionar en múltiples alfabetizaciones, postulan la competencia mediática que es a la vez digital y multimodal (Gee y Hayes, 2011; Gutiérrez y Tyner, 2012).

Lamentablemente, el uso del concepto competencia añade un elemento adicional al confuso paisaje de conceptos en este ámbito investigativo. Conviene, entonces, intentar ciertas aclaraciones. El uso del término se extiende a partir de la línea que comienza Ferrés, et al. (2011), muy prolífica en investigaciones empíricas (Aguaded et al.,2011;Ferrés y Santibáñez, 2011; GarcíaRuiz, Ramírez-García y Rodríguez-Rosell, 2014; Gozálvez y Zeballos, 2013). Sus investigaciones se alinean con un proceso de definición de habilidades transversalmente adquiridas por poblaciones situadas en diversas ubicaciones geográficas (competencias clave) con el modelo propiciado por la Unión Europea en sus declaraciones de Bolonia, Lisboa y Barcelona en torno a una formación transversal a nivel europeo, con intereses de estandarización (Gimeno, 2008) en la medición de la competencia mediática (Ferrés, 2007; Ferrés et al., 2011).

La confusión se genera por el uso indistinto que en la extensión de las investigaciones empíricas mencionadas se hace de los conceptos competencia y alfabetización, lo que resulta complejo en un ámbito investigativo con tanta polisemia (Martens, 2010).

Más allá de este uso indistinto, tanto en la propuesta recién mencionada, como en la de la UNESCO, e incluso en las que refieren a alfabetizaciones parceladas, se puede apreciar la incidencia de una visión de la alfabetización como conjunto de competencias (Buitrago et al., 2017). Esto plantea una segunda distinción relacionada con el alcance y abordaje de la alfabetización.

\section{Alfabetización como competencia o alfabetización como literacidad}

La conceptualización de la línea investigativa iniciada por Ferrés (2007) en torno a la competencia mediática se adscribe a la posición mayoritaria de quienes investigan la media literacy, en el sentido de perseguir la adquisición de una serie de conocimientos y habilidades genéricos y estandarizados, dejando en segundo plano el contexto sociocultural que en la práctica mediática ocurre (Martens, 2010). No obstante, se debe precisar que no todas las perspectivas que siguen la tendencia mayoritaria son iguales. Leaning (2009) diferencia, entre aquellas, que buscan prevenir a los sujetos de los efectos negativos de los medios (Potter, 2010) desde una perspectiva de inoculación (cognitiva); y las que plantean una mirada más activa y crítica (Kellner y Share, 2005), desmitificadora de algún modo. 
doi: http://dx.doi.org/10.15359/ree.22-2.8

URL: http://www.una.ac.cr/educare

CORREO: educare@una.cr

Independiente de los matices, los enfoques que relevan la adquisición, ya sea de un código o de una competencia -que acreditan niveles de logro estandarizados de parte de los sujetosrestan atención al contexto sociocultural en el que se desarrollan las prácticas mediáticas, aspecto que es clave para dar sentido al aprendizaje y a la labor educativa (Martens, 2010). La disponibilidad de las tecnologías digitales permite una visión que, en el marco de las prácticas educativas, resulta de gran potencial, pues según Buckingham (2003), hay que hacerse cargo de que hoy las personas, en particular niños, niñas y jóvenes, tienen conocimientos y experiencias previas respecto de los medios de comunicación y las tecnologías digitales tan enraizadas en su cotidianidad, que esto no puede ser obviado o excluido. En este sentido, la acción educativa y pedagógica debe prestar atención a esos contextos socioculturales y a las relaciones que los sujetos a alfabetizar tienen con los medios y tecnologías digitales.

La perspectiva de la educación basada en competencias es criticada por suponer una uniformización del saber (Gimeno, 2008). Sin embargo, aun cuando se excluyen las condiciones socioculturales de las prácticas mediáticas, la propuesta de Ferrés (2007) se centra más que en las prácticas pedagógicas o en las actividades evaluativas del contexto escolar cotidiano, en evaluaciones generales, para evaluar el desempeño de las políticas curriculares. El autor señala que "la eficacia de los procesos de enseñanza y aprendizaje está condicionada en buena medida por la eficacia de los sistemas de evaluación que se incorporan" (Ferrés y Santibáñez, 2011, p. 12) a lo que añade: "LLa evaluación del grado de competencia mediática] pretende contribuir a potenciar el desarrollo de una política de educación mediática, y a perfilar los objetivos, los contenidos, los procedimientos y las actitudes que son necesarias desarrollar en este ámbito" (p. 15). Algo muy similar a lo que ocurre con la propuesta de UNESCO, que, como se mencionó, plantea más una plataforma de reflexión sobre políticas nacionales, que un mecanismo pormenorizado de la educación en medios en el aula u otros espacios sociales. Por lo tanto, es importante tener en consideración el propósito y orientación política y educativa de la investigación en alfabetización mediática relacionada al desarrollo de competencias. Si el propósito es contribuir a la definición de metas universales o nacionales, probablemente la competencia aporte en ello; ahora, si lo que se desea es establecer orientaciones para que los procesos de alfabetización mediática ocurran de manera pertinente, consistente y significativa en toda la población, esta perspectiva es insuficiente.

Por ello, para que este enfoque no quede incompleto, necesita ser complementado por una comprensión de la alfabetización como literacidad, como adquisición de un lenguaje a través de la práctica mediática, donde opera mucho más la acción específicamente pedagógica de la educación mediática. 


\section{Aprendizaje, alfabetización mediática y lenguaje}

Desde una perspectiva que contribuya en los vacíos mencionados respecto de la conceptualización de las alfabetizaciones mediáticas, el trabajo de Gee (2004) puede ser un aporte significativo, pues introduce dos elementos clave en la discusión: el lenguaje y sus posibilidades expresivas, y el aprendizaje en tanto proceso que permite su adquisición y desarrollo.

Si bien la alfabetización está desde sus orígenes asociada al proceso de lecto-escritura, la inclusión del lenguaje permite ampliar dicha perspectiva, y ser coherente con el actual escenario mediático y digital, donde adquieren importancia otros sistemas semióticos.

El lenguaje (verbal) se puede ver como un set de convenciones sociales acerca de cómo se combinan palabras, frases y sentencias para comunicar significados. Estas combinaciones gramaticales de palabras son expresadas tanto vía discurso oral, como a través de signos y escritura (Gee y Hayes, 2011). Para estos autores la alfabetización constituye una de las tecnologías que facilita el lenguaje verbal, mas no la única, pues el lenguaje escrito es un invento relativamente reciente dentro de la historia de la comunicación humana, al que precede el lenguaje oral, mucho anterior a la escritura. Ahora, la característica principal de la alfabetización es que permite la deslocalización y amplificación en tiempo y espacio de los significados, permitiendo llegar a contextos no presentes ni directos (Gee y Hayes, 2011).

Sus estudios destacan el hecho de que el lenguaje en sí mismo es, y siempre ha sido, una mezcla de sonidos, palabras, imágenes creadas en las mentes y gestos, usados en contextos llenos de objetos, sonidos, acciones e interpretaciones. A esto refiere la multimodalidad del lenguaje, y esta característica es uno de los aspectos centrales en los nuevos medios y tecnologías digitales. Como señala Gee (2004), estos plantean oportunidades y desafíos para el aprendizaje y la generación de conocimiento. En contraste con los medios masivos, que mantienen la separación de lo dicho con quién dice y dónde, y postergan la conversación más allá del acá y ahora; los nuevos medios y tecnologías digitales presentarían un escenario donde el diálogo se lleva de vuelta a este fundamento más conversacional, interactivo del acá y ahora: de vuelta a su posibilidad multimodal.

Esto replantea, además, la posibilidad de generación de conocimiento y de aprendizaje, pues podría distanciarse de la construcción de conocimiento experto, relevando la generación de inteligencia y sabiduría colectiva, de traspaso de los conocimientos entre amateurs, dando con ello, espacio a una mayor diversidad de contenidos y formas de expresión. Si bien el lenguaje ha sido siempre multimodal, hoy es más persuasivo y diverso que antes (Gee y Hayes, 2011).

Con lo anterior se desprende que el aprendizaje requiere, a su vez, de una definición coherente con estos escenarios de mayor multimodalidad y flexibilidad. En principio, supone reconocer las particularidades de los escenarios, contextos, actividades y entes mediadores que están en juego. Ello implica entender el aprendizaje como un fenómeno social y situado 
doi: http://dx.doi.org/10.15359/ree.22-2.8

URL: http://www.una.ac.cr/educare

CORREO: educare@una.cr

(Lave, 1991; Wertsch, 1999). En este sentido, no solo se aprende sobre un contenido, sino que también se aprende a participar en el escenario, adquiriendo las prácticas y las normas que organizan la participación en una comunidad de práctica (Gee, 2004; Lave y Wenger 1991). Los nuevos medios y tecnologías digitales presentan ciertas características que permitirían redefinir los procesos que con frecuencia se caracteriza el aprendizaje. En particular, cabe mencionar dos: la participación con doble rol simultáneo, es decir, enseñante aprendiz; y la utilización de estrategias de exploración, experimentación y la colaboración con otras personas.

Tal vez, acá está el principal desafío que enfrentan las escuelas, quienes educan y los sistemas educacionales: reconocer e incorporar los nuevos aprendizajes, las nuevas formas de participación que algunos niños, niñas y jóvenes experimentan, y que otros grupos tienen como potencial horizonte de desarrollo.

\section{Reflexiones finales}

A partir de los recorridos conceptuales antes expuestos, es posible establecer algunos aspectos que parecen centrales a la hora de delimitar los objetos y conceptos propios de la educomunicación en el escenario actual de transformaciones sociales.

Si bien el campo de la comunicación-educación puede presentar algunos vacíos conceptuales que, por ahora, impiden abordar y comprender en su total complejidad las prácticas mediáticas actuales de niños, niñas y jóvenes, sí aporta en experiencias de cómo perfilar las claves, discutiendo y articulando coordenadas. Así se aprecia en las trayectorias sistematizadas desde América Latina. Sin embargo, se hacen necesarios la consideración y diálogo con los aportes que, desde las disciplinas que configuran los campos de educación y comunicación (juntos y por separado), pueden enriquecer el conocimiento de los fenómenos edu-comunicativos. Esto en especial, si se asume una perspectiva teórica socio-histórica como es el caso del trabajo presentado, pues la educación y el aprendizaje tienen, en la base, procesos comunicativos que los hacen posibles, y donde el lenguaje o los lenguajes son pieza fundamental.

Un segundo aspecto que resulta clave es la necesidad de incorporar en la discusión sobre alfabetización mediática, objeto de este artículo, los fenómenos del aprendizaje y de la multimodalidad en el lenguaje, pues por medio de ellos se puede dar cuenta de las particularidades que presentan los escenarios y tecnologías digitales, y los nuevos medios, para avanzar en el conocimiento de las prácticas mediáticas y las transformaciones sociales que ellas suponen. Esto permitiría complementar y perfilar con mayor precisión las orientaciones educativas que ofrecen las perspectivas de alfabetización mediática de mayor influencia, y que, como se señaló, parecen más pertinentes para la promoción y orientación de políticas educativas y comunicativas a escala nacional o regional. 
Una educación que asuma el desafío de formar y promover una participación activa y crítica en los escenarios mediáticos y digitales que hoy son cotidianos requiere de la definición de las habilidades relevantes; los procesos de alfabetización más adecuados; y sobre todo, debe tener en consideración las experiencias y prácticas mediáticas de los sujetos en los que se busca el desarrollo de dichas habilidades.

\section{Referencias}

Aguaded-Gómez, J. I. (2012). La competencia mediática, una acción educativa inaplazable. Comunicar, 39(20), 7-8. doi: https://doi.org/10.3916/C39-2012-01-01

Aguaded, J. I., Ferrés, J., Cruz, M., Pérez, M., Sánchez J. y Delgado, Á. (2011). El grado de competencia mediática en la ciudadanía andaluza. Andalucía: Grupo Comunicar. Recuperado de http://rabida.uhu.es/dspace/bitstream/handle/10272/6892/Grado de competencia mediatica.pdf?sequence $=2$

Ardévol, E., Gómez-Cruz, E., Roig, A. y San Cornelio, G. (2010). Prácticas creativas y participación en los nuevos media. Quaderns del CAC, 13(1), 27-38. Recuperado de http://www.cac.cat/ pfw files/cma/recerca/quaderns cac/Q34 Ardevol et al. ES.pdf

Buckingham, D. (2003). Educación en medios. Alfabetización, aprendizaje y cultura contemporánea. Barcelona: Paidós.

Buckingham, D. (2007). Media education goes digital: An introduction. Learning, Media and technology, 32(2), 111-119. doi: https://doi.org/10.1080/17439880701343006

Buitrago, A., García, A. y Gutiérrez, A. (2017). Perspectiva histórica y clave actuales de la diversidad terminológica aplicada a la educación mediática. edmetic, 6(2), 81-104. doi: https://doi. org/10.21071/edmetic.v6i2.7002

Catts, R. y Lau, J. (2008). Towards information literacy indicators. Paris: UNESCO. Recuperado de http://unesdoc.unesco.org/images/0015/001587/158723e.pdf

Cazden, C. B. (1991). El discurso en el aula: El lenguaje de la enseñanza y del aprendizaje. Barcelona: Paidós.

CENECA. (1992). Educación para la comunicación. Manual latinoamericano. Santiago: CENECA/ UNICEF/ UNESCO.

Couldry, N. (2004). Theorising media as practice. Social Semiotics, 14(2), 115-132. doi: https://doi. org/10.1080/1035033042000238295

De Fontcuberta, M. (2001). Comunicación y educación: Una relación necesaria. Cuadernos. Info, 14, 140 -147. doi: https://doi.org/10.7764/cdi.14.190 
doi: http://dx.doi.org/10.15359/ree.22-2.8

URL: http://www.una.ac.cr/educare

CORREO: educare@una.cr

English Oxford living dictionaries. (s. f.). Literacy. Recuperado de https://en.oxforddictionaries. com/definition/literacy

Espitia, U. y Valderrama, C. E. (2009). Hacia una apertura política del campo comunicacióneducación. Nómadas, 30, 164-179. Recuperado de http://www.scielo.org.co/pdf/noma/ n30/n30a13.pdf

Ferrés, J. (2007). La competencia en comunicación audiovisual: Dimensiones e indicadores. Comunicar, 15(29), 100-107. Recuperado de https://www.revistacomunicar.com/index.ph p? contenido $=$ detalles\&numero $=29$ \&articulo $=29-2007-17$

Ferrés, J. y Santibáñez, J. (2011). Informe de investigación. Competencia mediática. Investigación sobre el grado de competencia de la ciudadanía en la Comunidad Autónoma de La Rioja. La Rioja: Grupo comunicar y Universidad de la Rioja. Recuperado de https://issuu.com/ grupo-comunicar/docs/competencia-larioja

Ferrés, J., García, A., Aguaded, J. I., Fernández, J., Figueres, M. y Blanes, M. (2011). Competencia mediática. Investigación sobre el grado de competencia de la ciudadanía en España. Madrid: Ministerio de Educación, Instituto de Tecnología Educativa. Recuperado de http://rabida. uhu.es/bitstream/handle/10272/6876/Competencia mediatica.pdf?sequence $=2$

Freire, P. (1999). Pedagogía del oprimido. México: Siglo XXI.

García-Ruiz, R., Ramírez-García, A. y Rodríguez-Rosell, M. M. (2014). Educación en alfabetización mediática para una nueva ciudadanía prosumidora. Comunicar, 22(43), 15-23. doi: https:// doi.org/10.3916/C43-2014-01

Gee, J. P. (2004). Situated language and learning: A critical of traditional schooling. London: Routledge, Recuperado de http://networkedlearningcollaborative.com/wp-content/ uploads/2015/07/james-paul-gee-situated-language-and-learning-a-critique-oftraditional-schooling-2004.pdf

Gee, J. P. y Hayes, E. R. (2011). Language and learning in the digital age. New York: Routledge.

Gimeno, J. (2008). Diez tesis sobre la aparente utilidad de las competencias en educación. En Gimeno, J. (Ed.) Educar por competencias, ¿qué hay de nuevo? (pp. 15-58). Madrid: Morata.

Gozálvez, V. y Zeballos Clavijo, R. (2013). Las interacciones mediáticas de la juventud boliviana: La competencia mediática de jóvenes de La Paz. Chasqui, 124, 34-40. Recuperado de http://revistachasqui.org/index.php/chasqui/article/view/16/26

Gutiérrez, A.yTyner, K. (2012). Educación para los medios, alfabetización mediática y competencia digital. Comunicar, 19(38), 31-39. doi: https://doi.org/10.3916/C38-2012-02-03 
Huergo, J. A. (2000). Comunicación/Educación: Itinerarios transversales. En C. Valderrama (Ed.), Comunicación - educación: Coordenadas, abordajes y travesías (pp. 3-26). Santafé de Bogotá: Siglo del Hombre Editores.

Huergo, J. A. y Fernández, M. (1999). Cultura escolar, cultura mediática / intersecciones. Santa Fe de Bogotá: Universidad Pedagógica Nacional.

Hug, T. (2013). Competencia mediática y alfabetización visual. Hacia consideraciones más allá de las alfabetizaciones. Razón y Palabra, 18(83), 1-30. Recuperado de http://www.redalyc. org/articulo.oa?id=199527531037

Kaplún, M. (1987). El comunicador popular. Buenos Aires: Lumen-Humanitas.

Kellner, D. y Share, J. (2005). Toward critical media literacy: Core concepts, debates, organizations, and policy. Discourse: Studies in the cultural politics of education, 26(3), 369-386. doi: https:// doi.org/10.1080/01596300500200169

Koltay, T. (2011). The media and the literacies: Media literacy, information literacy, digital literacy. Media, Culture \& Society, 33(2), 211-221. doi: https://doi.org/10.1177/0163443710393382

Lave, J. (1991). La cognición en la práctica. Barcelona: Paidós. doi: https://doi.org/10.1017/ CBO9780511815355

Lave, J. y Wenger, E. (1991). Situated learning: Legitimate peripheral participation. New York: Cambridge University Press.

Leaning, M. (Ed.). (2009). Issues in information and media literacy: Criticism, history and policy. Santa Rosa: Informing Science Press. Recuperado de http://net-workingworlds.weebly. com/uploads/1/5/1/5/15155460/issues in $\mathrm{ml}$ leaning book.pdf

Livingstone, S. (2004). Media literacy and the challenge of new information and communication technologies. The Communication Review, 7(1), 3-14. doi: https://doi. org/10.1080/10714420490280152

Literat, I. (2014). Measuring new media literacies: Towards the development of a comprehensive assessment tool. Journal of Media Literacy Education, 6(1), 1-13. Recuperado de http:// digitalcommons.uri.edu/jmle/vol6/iss $1 / 2 /$

Martens, H. (2010). Evaluating media literacy education: Concepts, theories and future directions. The Journal of Media Literacy Education, 2(1), 1-22. Recuperado de http://digitalcommons. uri.edu/jmle/vol2/iss1/1/

Martín-Barbero, J. (2002). Oficio de cartógrafo. Travesías latinoamericanas de la comunicación en la cultura. Santiago: Fondo de Cultura Económica. 
doi: http://dx.doi.org/10.15359/ree.22-2.8

URL: http://www.una.ac.cr/educare

CORREO: educare@una.cr

Martín-Barbero, J. (2003). La educación desde la comunicación. Bogotá: Norma.

Mercer, N. (1997). La construcción guiada del conocimiento. El habla de profesores y alumnos. Barcelona: Paidós.

Morabes, P. (2014). Problemáticas emergentes en comunicación/educación. Aportes desde los estudios culturales. Oficios Terrestres, 30, 198-212. Recuperado de http://perio.unlp.edu. ar/ojs/index.php/oficiosterrestres/article/view/2163/2015

Pérez M. A. (2007). Declaración de Unesco en Grünwald (Alemania). Comunicar, 15(28), 122-125. Recuperado de http://www.redalyc.org/articulo.oa?id=15802816

Pérez, M. A. y Delgado, Á. (2012). De la competencia digital y audiovisual a la competencia mediática: Dimensiones e indicadores. Comunicar, 20(39), 25-34. doi: https://doi. org/10.3916/C39-2012-02-02

Pérez-Tornero, J. M. y Tayie, S. (2012). La formación de profesores en educación en medios: Currículo y experiencias internacionales. Comunicar, 20(39), 10-14. doi: https://doi. org/10.3916/C39-2012-02-00

Potter, W. J. (2010). The state of media literacy. Journal of Broadcasting \& Electronic Media, 54(4), 675-696. doi: https://doi.org/10.1080/08838151.2011.521462

Saleh, I. (2012). La educación en medios en Sudáfrica: Objetivos y herramientas. Comunicar, 20(39), 35-44. doi: https://doi.org/10.3916/C39-2012-02-03

Valderrama, C. E. (2000). Introducción. En C. E. Valderrama (Ed.), Comunicación - educación: Coordenadas, abordajes y travesías (pp IX-XXIII). Santafé de Bogotá: Siglo del Hombre Editores. Doi: https://doi.org/10.4000/books.sdh.180

Vygotski, L. S. (1978). El desarrollo de los procesos psicológicos superiores. Barcelona: Crítica.

Wertsch, J. (1999). La mente en acción. Buenos Aires: Aique.

Wilson, C. (2012). Alfabetización mediática e informacional: Proyecciones didácticas. Comunicar, 20(39), 15-24. doi: https://doi.org/10.3916/C39-2012-02-01

Wilson, C., Grizzle, A., Tuazon, R., Akyempong, K., \& Cheung, C. K. (2011). Media and information literacy curriculum for teachers. Paris: UNESCO. Recuperado de http://unesdoc.unesco.org/ images/0019/001929/192971e.pdf 